\title{
Determination of fat, protein, moisture, and salt content of Cheddar cheese using mid-infrared transmittance spectroscopy ${ }^{1}$
}

\author{
Brenda J. Margolies and David M. Barbano² \\ Northeast Dairy Foods Research Center, Department of Food Science, Cornell University, Ithaca, NY 14853
}

\begin{abstract}
The objective of our work was to develop and evaluate the performance of a rapid method for measuring fat, protein, moisture, and salt content of Cheddar cheese using a combination mid-infrared (MIR) transmittance analysis and an in-line conductivity sensor in an MIR milk analyzer. Cheddar cheese was blended with a dissolving solution containing pentasodium triphosphate and disodium metasilicate to achieve a uniform, particle-free dispersion of cheese, which had a fat and protein content similar to milk and could be analyzed using a MIR transmittance milk analyzer. Annatto-colored Cheddar cheese samples (34) from one cheese factory were analyzed using reference chemistry methods for fat (Mojonnier ether extraction), crude protein (Kjeldahl), moisture (oven-drying total solids), and salt (Volhard silver nitrate titration). The same 34 cheese samples were also dissolved using the cheese dissolver solution, and then run through the MIR and used for calibration. The reference testing for fat and crude protein was done on the cheese after dispersion in the dissolver solution. Validation was done using a total of 36 annatto-colored Cheddar cheese samples from 4 cheese factories. The 36 validation cheese samples were also analyzed using near-infrared spectroscopy for fat, moisture, and the coulometric method for salt in each factory where they were produced. The validation cheeses were also tested using the same chemical reference methods that were used for analysis of the calibration samples. Standard error of prediction (SEP) values for moisture and fat on the near-infrared spectroscopy were 0.30 and 0.45 , respectively, whereas the MIR produced SEP values of 0.28 and 0.23 for moisture (mean $36.82 \%$ ) and fat (mean $34.0 \%$ ), respectively. The MIR also out-performed the coulometric method for
\end{abstract}

\footnotetext{
Received July 2, 2017.

Accepted September 14, 2017.

${ }^{1}$ Use of names, names of ingredients, and identification of specific models of equipment is for scientific clarity and does not constitute any endorsement of product by authors, Cornell University, or the Northeast Dairy Foods Research Center.

${ }^{2}$ Corresponding author: dmb37@cornell.edu
}

salt determination with SEP values of 0.036 and 0.139 at a mean level of salt of $1.8 \%$, respectively. The MIR had an SEP value of 0.19 for estimation at a mean level of $24.0 \%$ crude protein, which suggests that MIR could be an easy and effective way for cheese producers to measure protein to determine protein recovery in cheese making.

Key words: mid-infrared, Cheddar cheese, composition

\section{INTRODUCTION}

Measurement of cheese yield, recovery of fat and protein, and evaluation of cheese composition control in large-scale cheese factories is an important aspect of cheese factory management. A system for evaluation and control of these parameters was reported by Margolies et al. (2017). During the testing of a cheese yield evaluation system in large commercial cheese factories, it was observed that the daily mean bias error in measurement was as high as $\pm 0.5 \%$ for fat and moisture in commercial cheese factories. It was concluded that the accuracy of rapid secondary testing methods needed improvement (Margolies et al., 2017).

The chemical reference methods for measurement of fat (e.g., Babcock and Mojonnier ether extraction), CP (Kjeldahl), moisture (forced air oven-drying), and salt (Volhard silver nitrate titration) are accurate but are too slow and impractical for rapid analysis of large numbers of cheese samples in a commercial quality assurance (QC) laboratory. Therefore, more rapid and cost-effective methods such as near-infrared (NIR) reflectance for fat, protein, and moisture (RodriguezOtero et al., 1995; McKenna, 2001) and coulometric methods (Varcoe, 2001) for salt determination are currently used in cheese factories.

The NIR methods for measurement of cheese composition use partial least squares (PLS) calibration models that are developed locally in each cheese factory and often require a large number of cheese samples (200 to 400) of each cheese type to be tested by reference chemistry and the NIR within each cheese factory (McKenna, 2001; Barbano and Lynch, 2006). Although using NIR for cheese composition analysis is 
appropriate in terms of the ease of sample preparation and speed of analysis, the work required to develop calibrations for each cheese type within each cheese factory is not practical or cost effective. Holroyd (2011) indicated that there has been an evolution of equipment manufacturer-specific NIR calibration approaches using multiple linear regression and PLS over the years. If a factory has more than one NIR analyzer within their laboratory, separate calibration development may be required for each instrument. The accuracy of each prediction model for each cheese type is dependent on the accuracy of the reference chemistry performed in the cheese factory and the concentration range and distribution of fat, protein, and moisture in the specific calibration samples used for PLS model development (McKenna, 2001; Barbano and Lynch, 2006). Consistency of sample presentation (particle size distribution) is often a source of analytical variation in NIR cheese analysis (Holroyd, 2011). In a review of NIR analysis of cheese, Holroyd (2011) gave the Fonterra Research Centre (Palmerston North, New Zealand) perspective on the evolution of NIR analysis of cheese for a large group of cheese factories in New Zealand over the last $30 \mathrm{yr}$, and on the evolution of NIR analytical technology. Holroyd (2011) reported that the following factors are important in NIR cheese analysis: (1) careful sample preparation using several cheese cores from each block, (2) representative sampling of the block, (3) a knowledge of the sample matrix, and (4) sample preparation that provides a uniform presentation of the sample to the NIR. The accuracy of analytical performance of an indirect measurement method's prediction of reference chemistry is called the standard error of prediction (SEP). Holroyd (2011) reported the SEP metrics from many studies of NIR cheese analysis performance ranging from 0.2 to $0.5 \%$ for fat, protein, and moisture during the period from 1993 to 2003. In 2003, Fourier transform NIR instruments became more common and some individual companies developed global PLS models for cheese analysis that reduced the amount of reference chemistry, time, and cost required at the local level for calibration, while maintaining SEP values more consistently in the range of 0.2 to $0.35 \%$ for fat and moisture prediction (Holroyd, 2011).

Mid-infrared (MIR) milk analyzers are commonly used in cheese factories for analysis of milk, cream, and liquid whey products. The understanding of measurement of fat and protein using MIR is well developed (Kaylegian et al., 2006b, 2009) and accepted in official methods for milk (AOAC International, 2016, method number 972.16). While various instrument manufacturers have developed applications notes for analysis of cheese samples using MIR liquid analyzers, utilization of this approach for cheese analysis is not common. Unlike
NIR, MIR methods use well documented wavelengths for measurement of fat, protein, and lactose (Kaylegian et al., 2009) and this approach could be applied to cheese analysis. The challenge is sample preparation to convert the solid cheese into a particle-free liquid that could be pumped through the MIR milk analyzer flow system. A method for dissolving cheese for MIR analysis was described by Sjaunja (1999) using a solution of disodium metasilicate and pentasodium triphosphate. The potential advantage of this approach would be that liquid calibration samples might be prepared centrally and used on multiple instruments in multiple factories as is currently done for milk (Kaylegian et al., 2006a, 2006b) and whey analysis by MIR. This would reduce the need for reference chemistry analysis of cheese in cheese factories and provide an analytical alternative to NIR analysis of cheese using a piece of equipment that is normally available in cheese factories. The objective of our work was to develop and evaluate the performance of a rapid method for measuring fat, protein, moisture, and salt content of Cheddar cheese using a combination MIR transmittance analysis and an in-line conductivity sensor within the MIR milk analyzer.

\section{MATERIALS AND METHODS}

\section{Experimental Design}

Calibration. Cheese samples were diluted about 10:1 (wt/wt) with a dispersing liquid, blended, and pumped through a MIR milk analyzer (LactoScope FTIR Advanced, Delta Instruments, Drachten, The Netherlands). Cheese samples were between 5 and $10 \mathrm{~d}$ of age at the time of analysis. Calibration of the MIR milk analyzer was done using 34 individual annatto-colored full-fat Cheddar cheese samples that represented different individual batches of cheese from one large commercial cheese factory. Reference chemistry for fat, protein, salt, and TS was determined for each cheese sample and a linear slope and intercept adjustment was made for estimation of fat (separately for fat A, B, and $\mathrm{A}+\mathrm{B}$ ), protein, salt, and TS. Fat $\mathrm{A}$ is a fat measurement based on the carbonyl stretch and fat B is based on carbon hydrogen stretch within neutral and polar lipids (Kaylegian et al., 2009). Moisture was calculated as 100 minus TS.

Validation. Whereas the calibration was based on full-fat annatto-colored Cheddar cheese from one factory, validation was done with 36 full-fat annatto-colored Cheddar cheeses from 4 different factories (6 from each of 2 factories and 12 from each of the other 2 factories). One of the 4 factories ( 6 cheese samples) was the same factory that produced the cheeses used as the 34 calibration samples for the MIR. Cheeses from different 
cheese factories were used to determine if the calibration developed for cheese produced in one factory was robust enough to be applied across multiple factories. Reference chemistry for all cheese samples was done by the Cornell University laboratory. The validation cheese samples from each factory were analyzed for fat, moisture, and salt in their own factory using their locally calibrated NIR for fat and moisture and either the coulometric method or NIR method for salt analysis. The data from the in-factory cheese analysis were reported and the performance of each locally calibrated NIR for predicting fat and moisture, the in-factory method for predicting salt, were compared with the results of MIR and reference chemistry. All factories had coulometric salt testing equipment and 3 out of 4 factories had a NIR calibration for salt. In those factories it was common practice to use the 2 methods interchangeably. We did not adjust the calibration of their local testing methods, and the results reported by the plants were the results that they would use in their cheese quality control.

\section{Cheese Analysis}

Cheese Grinding and Storage. Cheese samples $\left(4^{\circ} \mathrm{C}\right)$ were cut into 1 -cm cubes and then ground using a blender (E8442, Eberbach Corporation, Ann Arbor, MI) until a homogeneous particle size of about 3 to $4 \mathrm{~mm}$ was achieved. Ground cheese was packed into 90-g snap-lid vials (CPP03EDM-CL, Capitol Plastic Products, Amsterdam, NY) and kept at $4^{\circ} \mathrm{C}$ until testing. The vials were filled to the top with no head space to minimize loss of moisture from the cheese into the head space. At the time of weighing, the top $2 \mathrm{~cm}$ of cheese in the vial was discarded due to possible loss of moisture during storage. Separate vials of cheese were saved for moisture, fat, protein, and salt determination.

Cheese Dissolver Solution. The cheese dissolver solution (Sjaunja, 1999) was prepared by combination of $12.7 \mathrm{~g}$ of pentasodium triphosphate $\left(\mathrm{Na}_{5} \mathrm{P}_{3} \mathrm{O}_{10}\right)$ and $5.3 \mathrm{~g}$ of disodium metasilicate $\left(\mathrm{Na}_{2} \mathrm{Si}_{2} \mathrm{O}_{3}\right)$ in $1,982 \mathrm{~g}$ of water at $40^{\circ} \mathrm{C}$ and then stored at room temperature. This cheese dissolver chemical is available from the equipment manufacturer (MA00090055, Delta Instruments) in a premixed form. Dissolver solution was prepared fresh each week.

Cheese Preparation Using Cheese Dissolver. Cheese dissolver solution was heated to $65 \pm 2^{\circ} \mathrm{C}$ and approximately $81.0 \mathrm{~g}$ of dissolver solution was added to a 120-g capacity snap-lid vial (CPP04, Capitol Plastic Products). The dissolver plus vial weight was recorded to 4 decimal places, dissolver was transferred into a high shear stainless steel blender jar with a stainless steel blade assembly and stainless steel cap (E8580, Eberbach Corporation), and the weight of the vial plus residual dissolver was recorded. The weight of dissolver transferred into the blender jar $(81 \pm 0.2 \mathrm{~g})$ was calculated by difference. Next, $9 \pm 0.05 \mathrm{~g}$ of ground cheese was placed in a plastic 150-mL cup (RK5, Fabri-Kal, Kalamazoo, MI) and the weight of the cheese plus cup was recorded. The cheese was transferred into the high shear blender jar containing the warmed dissolver. The empty cup was recorded and the weight of cheese transferred to the blender jar was calculated as the difference.

Prior to blending, 3 drops of antifoam (MA00090060, Delta Instruments) were added to the high shear blender jar. The cheese samples were weighed and blended one at a time to achieve more consistent temperature of the dissolver/cheese mixture during blending. The stainless steel blender jar was placed on a 2-speed blender base (E8420, Eberbach Corporation). The blender jar was capped and run at low speed for $15 \mathrm{~s}$, followed by high speed for $45 \mathrm{~s}$, then the liquid was poured into a snap-lid plastic 120-g vial (CPP04, Capitol Plastic Products). When pouring the liquid into a clear snaplid plastic vial, the analyst can observe the liquid and see if any cheese particles remain. Our experience was that the blending worked very well with very few small cheese particles in the liquid. If for some reason a particle of cheese remained stuck on the side above the liquid level in the blender jar, the liquid was be poured back into the blender jar and blended for another 15 $\mathrm{s}$ on high speed to disperse the remaining particle(s). The closed plastic vial containing the blended cheese plus solver was placed in the $40^{\circ} \mathrm{C}$ water bath for about 20 min to allow the foam to break and entrapped air to dissipate. A portion of the blended cheese solution was run through the MIR analyzer and other portions were removed for determination of fat and protein by the Kjeldahl and Mojonnier ether extraction methods, respectively.

\section{Chemical Reference Methods}

Fat. The determination of fat content of cheese was done by analysis of the cheese that had been diluted and blended with dissolver $65 \pm 2^{\circ} \mathrm{C}$. This sample preparation produces a homogeneous liquid emulsion of the cheese. Analysis of the cheese plus dissolver achieved analytical repeatability that was comparable to that achieved with the Mojonnier method testing milk (Barbano et al., 1988; Wojciechowski et al., 2016). Cheese plus dissolver $(10 \mathrm{~g})$ was weighed into a Mojonnier ether extraction flask and tested in duplicate just like a milk sample (Barbano et al., 1988). The repeatability of the method was much better than running the ether 
extraction directly on $1 \mathrm{~g}$ of cheese. Duplicate tests on cheese plus dissolver were typically within $0.01 \%$ fat. The final result was then multiplied by the weight/ weight dilution factor (cheese plus dissolver) to calculate the amount of fat in the cheese.

Protein. For the determination of nitrogen content, the Kjeldahl method was used (Barbano and Clark, 1990; Lynch and Barbano, 1999) and the total nitrogen content was multiplied by 6.38 to determine total (crude, total $\mathrm{N} \times 6.38$ ) protein. Similar to the ether extraction, the Kjeldahl method was performed in duplicate on the cheese plus dissolver mixture. The Kjeldahl total nitrogen method used was the same as the official method used for milk (Barbano and Clark, 1990) and the analytical performance was similar to that of milk (Wojciechowski et al., 2016). The repeatability of the method was much better than when doing the Kjeldahl directly on $1 \mathrm{~g}$ of cheese. Duplicate tests were typically within $0.01 \%$ protein. The final result was then multiplied by the 6.38 total protein factor and the weight/ weight dilution factor (cheese + dissolver) to calculate the amount of protein in the cheese.

Salt. Cheese salt was determined in duplicate with the Volhard method (AOAC International, 2016, method number 935.43; SMEDP 15.052) directly on the cheese (approximately $3 \mathrm{~g}$ ), not a cheese + dissolver mixture. Cheeses were heated and digested with nitric acid and potassium permanganate in the presence of a known number of moles of silver nitrate. The acid digestion allows the chloride in the sample to be freed and reacted with the silver to form $\mathrm{AgCl}$. Salt content was determined by back-titration of the remaining unreacted silver using potassium thiocyanate with a ferric ammonium indicator.
Total Solids. The reference method for determination of the solids content of cheese was $24 \mathrm{~h}$ at $100^{\circ} \mathrm{C}$ in a forced-air oven using a 2-g sample (Hooi et al., 2004, method 15.114, section 9.3.1). Oven drying was done in triplicate for each cheese.

\section{Mid-Infrared Analysis}

Cheese was prepared using the dissolver as described above, and then allowed to degas in a $40^{\circ} \mathrm{C}$ water bath for approximately $20 \mathrm{~min}$ before being run through the MIR. Pre-calibration of the MIR and primary slopes for the main milk components were set as described by Lynch et al. (2006). The optimized virtual filter wavelengths and bandwidths used for fat B, lactose, protein, and fat A were as described by Kaylegian et al. (2009). As is the case with milk analysis, fat $\mathrm{A}+$ $\mathrm{B}$ was calculated as $[(0.7 \times$ fat $\mathrm{B}$ corrected $)+(0.3$ $\times$ fat $\mathrm{A}$ corrected)]. Intercorrection factors (Barbano and Clark, 1989; Lynch et al., 2006) for the instrument used in this study were the same as those used for milk. Salt was determined using an in-line conductivity sensor within the MIR pumping system. Total solids was calculated as the sum of $[($ fat $)+$ (protein $)+$ (salt) $]$ with a slope and intercept adjustment using the TS reference chemistry from oven-drying. Based on the analytical performance (i.e., lowest SEP) for fat, the fat measure (i.e., fat $\mathrm{A}$, fat $\mathrm{B}$, or a combination of fat $\mathrm{A}$ and $\mathrm{B}$ ) that gave the best analytical performance was used to provide the best prediction of TS using the equation above. The sample and reference filter wavelengths, scale, and intercorrection factors for the fat A, fat B, lactose, and protein used in the current study are shown in Table 1.

Table 1. Mid-infrared wavenumbers $\left(\mathrm{cm}^{-1}\right)$, scale, offset, and intercorrection factors for fat B, lactose, protein, and fat A traditional virtual filter wavelengths

\begin{tabular}{lcccc}
\hline Item & $\begin{array}{c}\text { First wave } \\
\text { number }\end{array}$ & $\begin{array}{c}\text { Last wave } \\
\text { number }\end{array}$ & Scale & Offset \\
\hline Sample filters & 2,838 & 2,864 & 34.6352 & 0.00 \\
Fat B & 1,038 & 1,058 & 17.6939 & 0.00 \\
Lactose & 1,531 & 1,551 & 21.6284 & 0.00 \\
Protein & 1,740 & 1,756 & 21.8407 & 0.00 \\
Fat A & 2,800 & 2,824 & -34.6352 & 0.00 \\
Reference filters & 1,286 & 1,300 & -17.6939 & 0.00 \\
Fat B & 1,485 & 1,497 & -21.6284 & 0.00 \\
Lactose & 1,783 & 1,799 & -21.8407 & 0.00 \\
Protein & Fat B & Lactose & Protein & Fat A \\
Fat A & 1.000 & -0.149 & -0.057 & 0.000 \\
\hline Intercorrection factors & 0.044 & 1.000 & 0.016 & 0.000 \\
\hline Fat B & 0.064 & 0.052 & 1.000 & 0.000 \\
Lactose & 0.000 & 0.024 & 0.020 & 1.000 \\
Protein & & & & \\
Fat A & & & & \\
\hline
\end{tabular}




\section{RESULTS AND DISCUSSION}

\section{Calibration}

The 34 annatto-colored cheese samples produced in one factory that were used for calibration of the MIR produced an SEP for fat $\mathrm{A}$, fat $\mathrm{B}$, fat $\mathrm{A}+\mathrm{B}$, moisture, protein, and salt of $0.115,0.110,0.110,0.092,0.074$, and 0.034 , respectively. The coefficient of determination $\left(\mathbf{R}^{2}\right)$ values were $0.91,0.92,0.92,0.92,0.95$, and 0.85 , respectively. Two consecutive measures of each blended cheese sample from the same vial were performed with the MIR. The mean difference (MD) and repeatability standard deviation $\left(\mathrm{S}_{\mathrm{r}}\right)$ of the absolute difference between 2 consecutive measures of each of the 34 blended cheese samples were 0.076 and 0.069 , 0.071 and $0.068,0.072$ and $0.068,0.080$ and 0.051 , 0.041 and 0.033 , and 0.009 and 0.009 , respectively, for fat $\mathrm{A}$, fat $\mathrm{B}$, fat $\mathrm{A}+\mathrm{B}$, moisture, protein, and salt. The relative standard deviations of repeatability were 0.21 , $0.20,0.20,0.14,0.14$, and $0.52 \%$ for fat $\mathrm{A}$, fat $\mathrm{B}$, fat $\mathrm{A}+\mathrm{B}$, moisture, protein, and salt, respectively.

\section{Validation}

An independent set of 36 annatto-colored Cheddar cheeses produced in 4 different factories were used for validation of the MIR method. Reference chemistry and NIR results were also available for each sample to use for comparison to the results produced by MIR. The regression analyses of reference moisture values as a function of predicted moisture by NIR (Figure 1A) and MIR (Figure 1B) both had similar $\mathrm{R}^{2}$ values of about 0.93. The regression analyses of reference fat values as a function of predicted fat by NIR (Figure 2A) and MIR (Figure 2B) had very different $R^{2}$ values of about 0.70 and 0.93 , respectively. For the NIR, each of the 4 factories calibrated their own NIR for fat, tested their own cheese samples by NIR, and reported fat percentages for their cheeses. The poor agreement between fat reference chemistry and NIR predictions could be due to inaccuracy in fat reference chemistry done in the cheese factory and that was used to calibrate their NIR or lack of robustness of the NIR PLS prediction model. In practice, this is what was seen in our survey of cheese factory analytical performance in the previous cheese yield and composition control study (Margolies et al., 2017).

The regression analyses of reference salt values as a function of predicted salt by the coulometric method (Figure 3A) and MIR (Figure 3B) had very different $\mathrm{R}^{2}$ values of about 0.16 and 0.94 , respectively. The large difference in prediction performance between the commonly used coulometric method in commercial cheese factories and the MIR was surprising, but the poor performance was consistent with observations of weakness in the quality of cheese analysis data observed in our previous study (Margolies et al., 2017). Protein content of cheese is not routinely measured in most cheese factories; however, protein makes a very important contribution to cheese yield. Therefore, a MIR protein prediction model was developed. The regression analyses of reference protein values as a function of predicted protein by MIR (Figure 4) had an $\mathrm{R}^{2}$ value of 0.82 . Considering the important effect cheese composition control has on cheese quality during aging, a method for routine cheese analysis that can achieve better agreement with reference chemistry than current practices is needed. Overall, the regression predictions of moisture, fat, salt, and protein by the MIR instrument appeared to be suitable for use in routine QC.

A comparison of mean test results on a factory-byfactory basis for moisture, fat, and salt is shown in Table 2. For moisture, agreement of the NIR and MIR means for all 36 cheeses with mean reference chem-

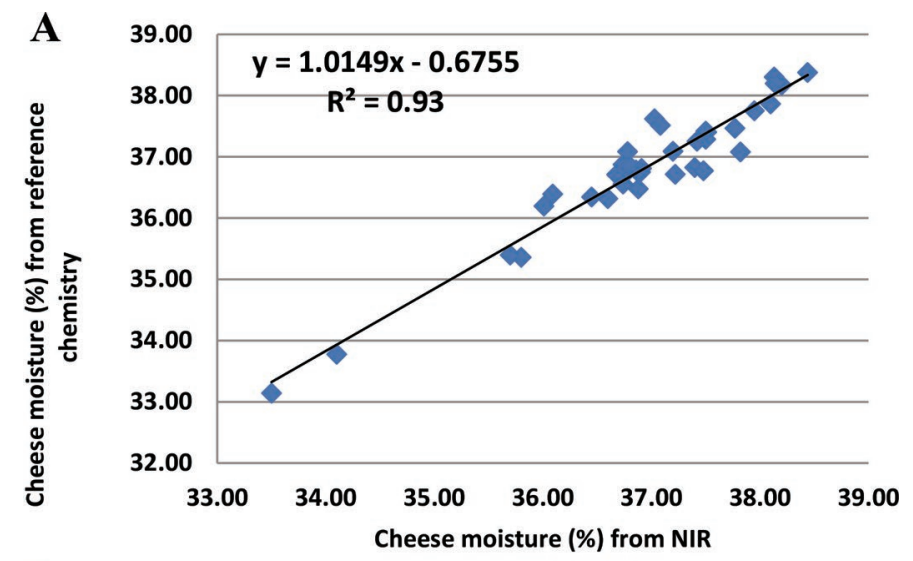

B

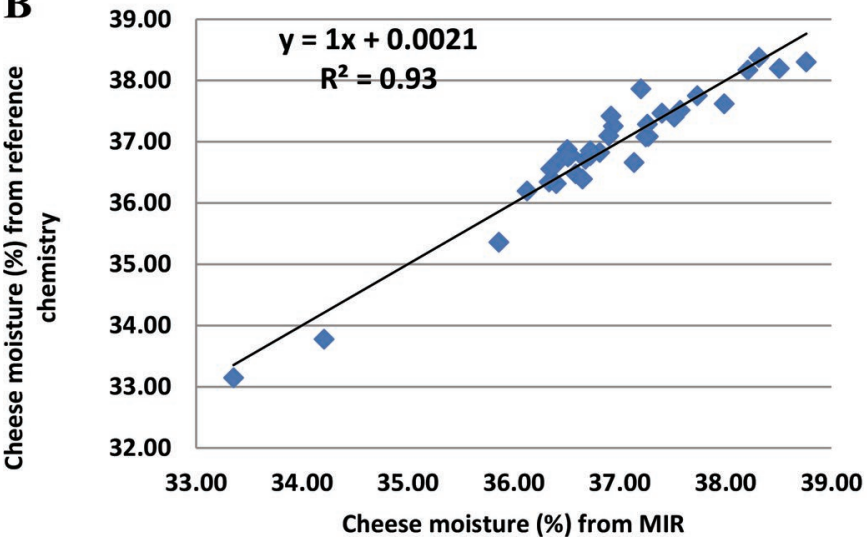

Figure 1. Predicted cheese moisture from (A) near-infrared (NIR) and (B) mid-infrared (MIR) and actual cheese moisture determined by reference chemistry oven-drying TS. Color version available online. 
A

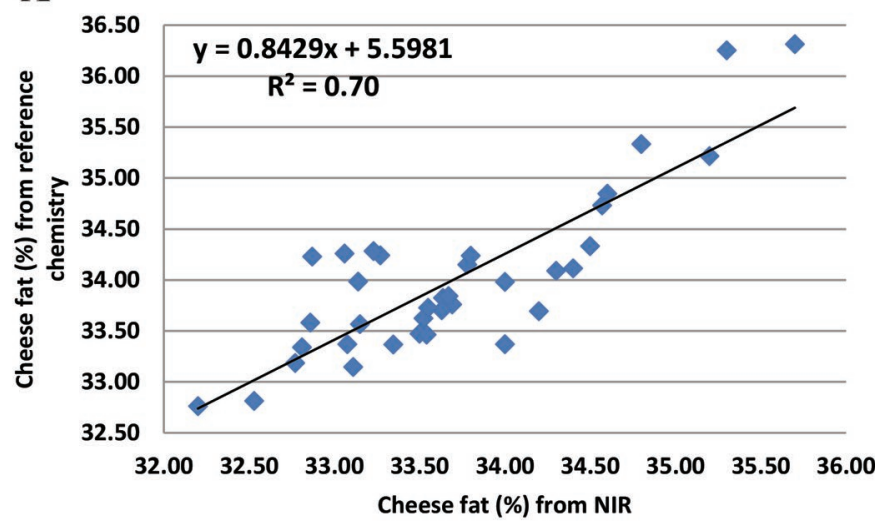

B

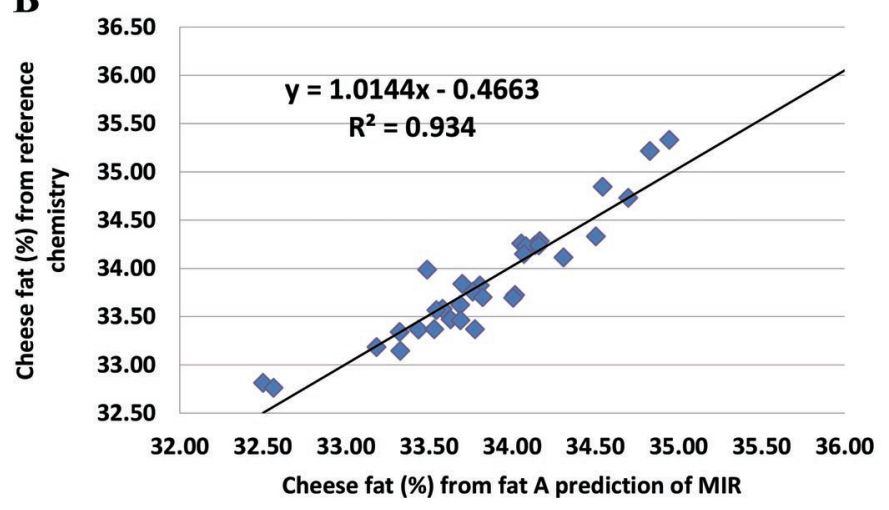

Figure 2. Predicted cheese fat from (A) near-infrared (NIR) and (B) mid-infrared (MIR) and actual cheese fat determined by reference chemistry Mojonnier ether extraction. Color version available online.

istry was the same for MIR and NIR, but standard deviation of the difference (SDD) between NIR and reference chemistry was larger (0.14) than the SDD between MIR and reference chemistry (0.09, Table 2). For fat, only MIR data for fat A is presented (Table 1) because, of the 3 MIR approaches for measurement of fat in Cheddar cheese, fat $\mathrm{A}$ had the best agreement with reference chemistry (to be discussed later). For fat, both MIR and NIR tested lower on average than the reference chemistry but the NIR results were further from reference chemistry, particularly in factory 1 , which had been reporting a problem with low fat recovery in cheese based on their NIR analysis data. It appears that the NIR fat calibration is not satisfactory in this factory. This is consistent with observations reported by Margolies et al. (2017). For fat, the SDD between NIR and reference chemistry was larger (0.42) than the SDD between MIR and reference chemistry (0.11, Table 2). For salt determination, the MIR gave slightly lower (0.09) mean results for all 34 cheeses than the reference method on validation (Table 2). The SDD between the MIR results and reference chemistry for salt was smaller (0.04) than the SDD between coulo-
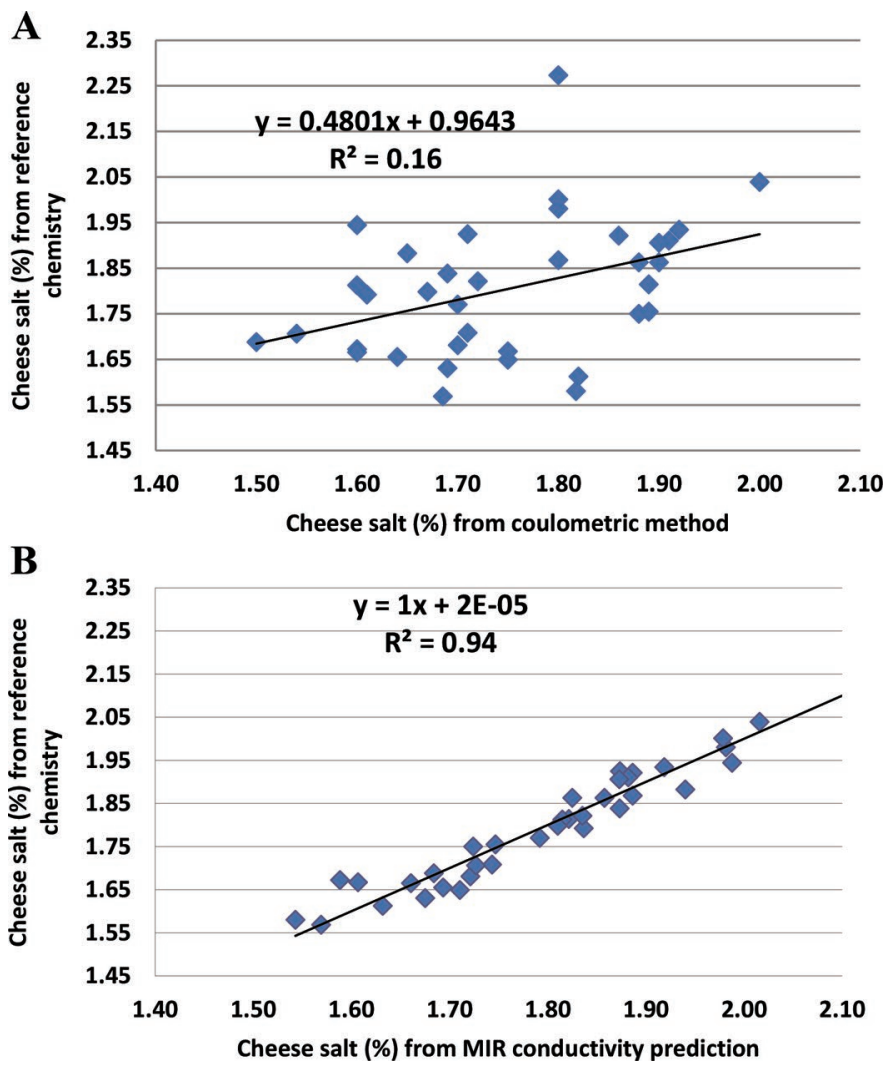

Figure 3. Predicted cheese salt from (A) coulometric method, and (B) mid-infrared (MIR) conductivity sensor and actual cheese salt determined by reference chemistry Volhard silver nitrate titration. Color version available online.

metric analysis and reference chemistry (0.14, Table 2). This suggests that a further adjustment of the slope and intercept of the MIR salt calibration would bring the MIR results into better agreement with reference chemistry than the coulometric method.

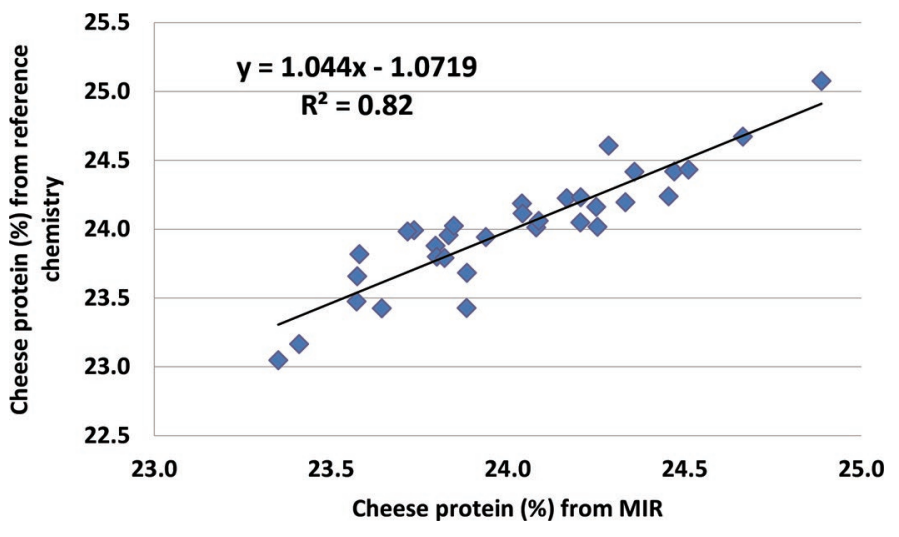

Figure 4. Predicted cheese CP from mid-infrared (MIR) and actual cheese CP determined by reference chemistry Kjeldahl method. Color version available online. 
Table 2. Comparison of mean and standard deviation of the difference (SDD) moisture (\%) and fat (\%) values with reference values for midinfrared (MIR) versus near-infrared (NIR) and coulometric method versus MIR for salt (\%) on a cheese factory by factory basis (factory 1,2 , 3 , and 4 represent the mean of $6,6,12$, and 12 annatto-colored Cheddar cheeses, respectively)

\begin{tabular}{|c|c|c|c|c|c|c|}
\hline Item & \multicolumn{3}{|c|}{ Moisture } & \multicolumn{3}{|c|}{ Moisture } \\
\hline SDD & \multicolumn{3}{|c|}{ Fat } & \multicolumn{3}{|c|}{ Fat } \\
\hline Factory & MIR (fat A) & Reference & Difference & NIR & Reference & Difference \\
\hline $\begin{array}{l}1 \\
2 \\
3 \\
4 \\
\text { Mean } \\
\text { SDD }\end{array}$ & $\begin{array}{l}33.81 \\
33.73 \\
33.43 \\
34.61 \\
33.89\end{array}$ & $\begin{array}{l}34.06 \\
33.75 \\
33.47 \\
34.65 \\
33.98\end{array}$ & $\begin{array}{r}-0.25 \\
-0.02 \\
-0.04 \\
-0.04 \\
-0.09 \\
0.11\end{array}$ & $\begin{array}{l}33.06 \\
33.50 \\
33.26 \\
34.57 \\
33.60\end{array}$ & $\begin{array}{l}34.06 \\
33.75 \\
33.47 \\
34.65 \\
33.98\end{array}$ & $\begin{array}{r}-0.99 \\
-0.25 \\
-0.21 \\
-0.04 \\
-0.37 \\
0.42\end{array}$ \\
\hline SDD & \multicolumn{3}{|c|}{ Salt } & \multicolumn{3}{|c|}{ Salt } \\
\hline Factory & MIR & Reference & Difference & Coulometric & Reference & Difference \\
\hline $\begin{array}{c}1 \\
2 \\
3 \\
4 \\
\text { Mean } \\
\text { SDD }\end{array}$ & $\begin{array}{l}1.61 \\
1.59 \\
1.75 \\
1.76 \\
1.68\end{array}$ & $\begin{array}{l}1.66 \\
1.69 \\
1.85 \\
1.89 \\
1.77\end{array}$ & $\begin{array}{r}-0.04 \\
-0.10 \\
-0.11 \\
-0.12 \\
-0.09 \\
0.04\end{array}$ & $\begin{array}{l}1.72 \\
1.82 \\
1.76 \\
1.73 \\
1.75\end{array}$ & $\begin{array}{l}1.66 \\
1.69 \\
1.85 \\
1.89 \\
1.77\end{array}$ & $\begin{array}{r}0.06 \\
0.13 \\
-0.10 \\
-0.16 \\
-0.02 \\
0.14\end{array}$ \\
\hline
\end{tabular}

The validation performance statistics for the NIR and MIR analysis of the 36 cheeses for moisture and fat is shown in Tables 3 and 4, respectively. Each factory QC laboratory tested their own cheeses with their NIR that was calibrated with cheese produced at their factory using their own reference chemistry and with the coulometric method. The SEP values for moisture and fat on the NIR, 0.30 and 0.45 (Table 3), respectively, were both higher than the values on the MIR, 0.28 and 0.23 (Table 4), for moisture and fat A (which had the best performance of all the fat measurements on the MIR), respectively. The MIR salt predictions followed a similar pattern, with the MIR outperforming the coulometric method with SEP values of 0.036 versus 0.139 , respectively. During the time of this study, none of the cheese factories were analyzing their cheese for protein content. The MIR had an SEP value of 0.19 for estimation of protein, which suggests MIR could be an easy and effective way for cheese producers to measure protein for determination of protein recovery in cheese

Table 3. Validation performance of near-infrared (NIR) on moisture (\%) and fat (\%) and the NIR/coulometric method for salt (\%) of 36 full-fat annatto-colored Cheddar cheeses from 4 different cheese factories

\begin{tabular}{|c|c|c|c|c|c|c|c|}
\hline Item & $\mathrm{N}$ & Reference & NIR & $\mathrm{MD}^{1}$ & $\mathrm{SDD}^{2}$ & $\mathrm{CV}$ & $\mathrm{SEP}^{3}$ \\
\hline Moisture & 34 & 36.82 & 36.95 & 0.13 & 0.29 & 0.79 & 0.30 \\
\hline \multirow[t]{2}{*}{ Fat } & 34 & 34.01 & 33.70 & -0.30 & 0.44 & 1.29 & 0.45 \\
\hline & \multicolumn{7}{|c|}{ NIR/coulometric method } \\
\hline Salt & 34 & 1.804 & 1.750 & -0.055 & 0.137 & 7.590 & 0.139 \\
\hline
\end{tabular}


making, similar to fat recovery. The SEP values for MIR using the sample analysis method described in the present study are very comparable to those reported by Holroyd (2011) for NIR, but were achieved with just a single calibration on the MIR for analysis of annatto Cheddar cheeses from 4 different cheese factories.

\section{Effect of Annatto Color on MIR Analysis}

In addition to the 36 annatto-colored Cheddar cheese validation samples, an additional 12 noncolored Cheddar cheese samples were also tested. It was found that the calibration that was done only with colored cheese samples did not predict well for the noncolored Cheddar cheese (data not shown). Of the 4 cheese plants that provided colored Cheddar cheese, 2 different annatto-colored concentrates were used (Material No. 70471, Chr. Hansen, Hørsholm, Denmark; item \#423506, D.D. Williamson Colors, LLC, Port Washington, WI). The concentrates of the annatto colors were diluted (1:4, vol/vol) with $0.01 \%$ (vol/vol) Triton X100 (Delta Instruments) solution in distilled water. The MIR absorbance spectra of the diluted annatto solutions were compared with the $0.01 \%$ Triton X-100 in water solution (Figure 5). The MIR instrument is normally adjusted to read zero on the $0.01 \%$ Triton $\mathrm{X}-100$ solution.

The concentrates of the annatto colors were diluted $(1: 4, \mathrm{vol} / \mathrm{vol})$ with $0.01 \%$ Triton $\mathrm{X}-100$ in water zeroing solution and compared with $0.01 \%$ Triton-water MIR zeroing solution (Figure 5). The spectra are shown (Figure 5) over a range of wavelengths that include the sample and reference wavelengths for fat A and protein (Table 1) because those were the only wavelengths used in the current study to predict cheese composition. The absorbance of the 2 color concentrates at the sample

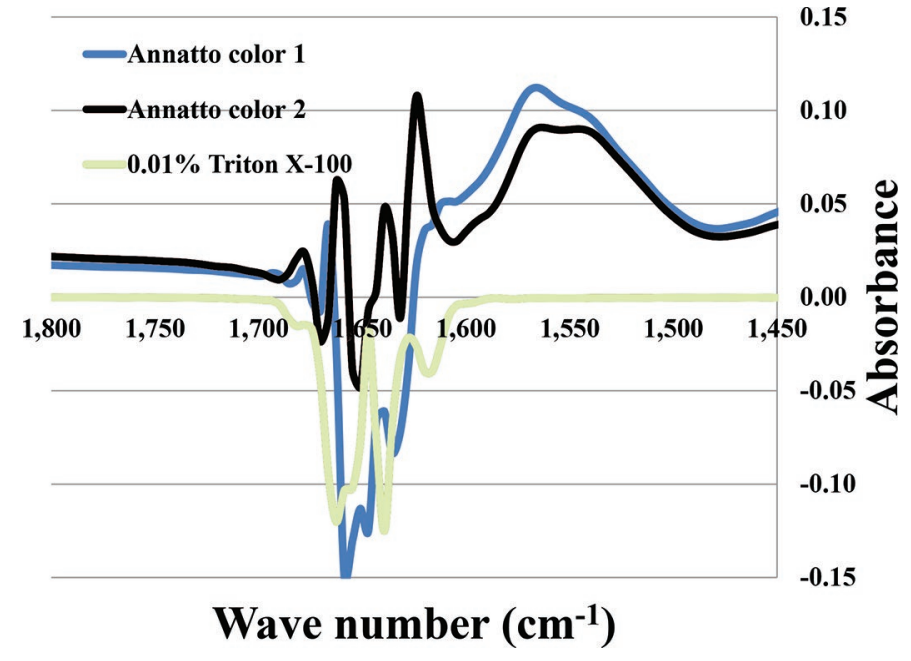

Figure 5. Mid-infrared (MIR) spectra of 2 commercial annatto color concentrates and a $0.01 \%$ Triton X-100 (Delta Instruments, Drachten, the Netherlands) solution in water in the range of wave numbers where the MIR fat A and protein measurements are done. Color version available online.

wavelengths for fat A (1,740 to $\left.1,756 \mathrm{~cm}^{-1}\right)$ and reference wavelengths for fat A (1783 to $1799 \mathrm{~cm}^{-1}$ ) were similar and had only a slightly higher intensity than the $0.1 \%$ Triton $\mathrm{X}-100$ in water solution, indicating that the color would have little effect on prediction of fat content of the cheese. However, the absorbance for the annatto color concentrates was much higher at the protein sample wavelengths $\left(1,531\right.$ to $\left.1,551 \mathrm{~cm}^{-1}\right)$ than it was for the protein reference wavelengths $(1,485$ to $1,497 \mathrm{~cm}^{-1}$ ) and the $0.1 \%$ triton solution. This demonstrates that the annatto coloring influences the ability of MIR to predict protein content and the calculated solids content of the cheese. Therefore, a separate calibration would be needed to be done for composi-

Table 4. Validation performance of mid-infrared (MIR) on moisture (\%), fat (\%), salt (\%), and CP (\%) for 36 full-fat annatto-colored Cheddar cheeses from 4 different cheese factories

\begin{tabular}{|c|c|c|c|c|c|c|c|}
\hline Item & $\mathrm{N}$ & Reference & $\mathrm{MIR}^{1}$ & $\mathrm{MD}^{2}$ & $\mathrm{SDD}^{3}$ & $\mathrm{CV}$ & $\mathrm{SEP}^{4}$ \\
\hline Moisture & 34 & 36.82 & 36.82 & 0.00 & 0.28 & 0.76 & 0.28 \\
\hline Fat $A^{5}$ & 34 & 34.01 & 33.94 & -0.07 & 0.23 & 0.67 & 0.23 \\
\hline Fat $B^{6}$ & 34 & 34.01 & 33.70 & -0.31 & 0.32 & 0.95 & 0.32 \\
\hline Fat $(\mathrm{AB})^{7}$ & 34 & 34.01 & 33.77 & -0.24 & 0.29 & 0.85 & 0.29 \\
\hline Salt & 34 & 1.804 & 1.705 & -0.100 & 0.035 & 1.950 & 0.036 \\
\hline Protein & 34 & 24.00 & 23.91 & -0.09 & 0.23 & 0.94 & 0.19 \\
\hline
\end{tabular}

${ }^{1} \mathrm{MIR}=$ mid infrared.

${ }^{2} \mathrm{MD}=$ mean difference

${ }^{3} \mathrm{SDD}=$ standard deviation of the difference between instrument and reference.

${ }^{4} \mathrm{SEP}=$ standard error of prediction.

${ }^{5}$ Fat $\mathrm{A}=$ fat prediction based on carbonyl stretch.

${ }^{6}$ Fat $\mathrm{B}=$ fat prediction based on $\mathrm{C}-\mathrm{H}$ stretch.

${ }^{7} \mathrm{Fat}(\mathrm{AB})=$ fat prediction based on combination of carbonyl and $\mathrm{C}-\mathrm{H}$ stretches. 
tion prediction of white Cheddar cheese by using white Cheddar for calibration, or an approach to compensate for the effect of annatto should be developed.

\section{Practical Aspects of Calibration of NIR and MIR in Commercial Cheese Factories}

The approaches to calibrate NIR and MIR for cheese analysis are very different. For NIR, each cheese variety within each factory requires a PLS calibration model developed for each measured parameter. The development of PLS models requires chemical analysis of 200 to 400 cheeses for each cheese type for each parameter to be measured (McKenna, 2001; Barbano and Lynch, 2006). In practice, this is very difficult for a QC laboratory in a cheese factory due to the challenge of maintaining the skilled staff members and equipment required to conduct high-quality reference chemistry testing. Additionally, calibrations are generally not easily transferable from one NIR instrument to another and are typically cheese type (e.g., Cheddar, Colby, Monterey Jack, and so on) and cheese factory specific. Recently, some NIR equipment manufacturers have been able to produce global PLS base calibrations that require less (10 to 20 samples) reference chemistry for a slope and intercept adjustment (Holroyd, 2011). The global model for NIR reduces the amount of reference chemistry that needs to be done by the cheese factory laboratory compared with development of the full PLS model in each factory. How well the global model predicts (i.e., SEP) needs to be determined within each factory.

The MIR instrument used in the current study was a standard MIR milk analyzer that is normally used to test milk, cream, and whey samples in a cheese factory. Because cheese is a solid, the analyst would not normally consider trying to test a cheese on an instrument designed for liquids. We have reported a method for liquification of cheese samples so that they can be tested like a milk or whey sample using a MIR milk analyzer. Thus, the MIR method requires additional time for sample preparation compared with NIR. In NIR, however, the consistency of sample grinding from analyst to analyst may influence results (Holroyd, 2011). Instead of developing PLS models on the MIR, we started with an evaluation of the performance of classical filter wavelengths (Kaylegian et al., 2009) used for measurement of fat and protein in milk analysis (Tables 1 and 4). This approach with MIR creates an opportunity for cheese factories to use a prepared set of liquid cheese calibration samples with reference chemistry done by a laboratory that specializes in calibration sample preparation and high quality reference chemistry. A cheese factory would purchase calibration samples for cheese analysis, just like they purchase samples for calibration of the same instrument for milk and whey analysis. This approach would reduce the need for reference chemistry to be done in the cheese factories and would allow cheese factories to achieve better analytical performance in cheese analysis used for cheese yield evaluation and composition control.

In our study the MIR was calibrated with 34 cheeses from one cheese factory and more accurately predicted the composition parameters of the cheeses from 3 different factories than NIR that was calibrated in each of those factories. For analysis of milk, a centrally produced calibration set is used across multiple factories and a similar approach could be applied to cheese testing using the MIR, thus saving time and resources normally required to calibrate an NIR, while attaining more accurate analyses.

\section{CONCLUSIONS}

A method for blending annatto-colored Cheddar cheese to form a liquid sample for MIR analysis gave equal or better performance than NIR and coulometric analysis of the same Cheddar cheese. The SEP values for moisture and fat on the NIR, 0.30 and 0.45 , respectively, were both higher than the SEP values on the MIR, 0.28 and 0.23 , for moisture and fat, respectively. Salt predictions followed a similar pattern, with the MIR out-performing the coulometric method with SEP values of 0.036 and 0.139 , respectively. The MIR had an SEP value of 0.19 for estimation of protein, which suggests that MIR could be an easy and effective way for cheese manufacturers to measure protein for determination of protein recovery in cheese making. A similar analytical approach using MIR might work for cottage cheese, sour cream, cream cheese, and other dairy products.

\section{ACKNOWLEDGMENTS}

The authors thank the Northeast Dairy Foods Research Center and the Department of Food Science at Cornell University (Ithaca, NY) for partial funding of this research. We appreciate the collaboration of Great Lakes Cheese, Adams, NY, AgriMark-Cabot Cheese in Chateaugay, NY, Cabot, VT, and Middlebury, VT, for providing cheese samples and analytical assistance on NIR and coulometric analysis of cheese. The technical assistance of laboratory staff members Chassidy Coon, Michelle Bilotta, and Sara Hatch from the Department of Food Science at Cornell University (Ithaca, NY) with analytical testing was greatly appreciated. 


\section{REFERENCES}

AOAC International. 2016. Official Methods of Analysis. 20th ed. AOAC International, Gaithersburg, MD.

Barbano, D., and J. Clark. 1989. Infrared milk analysis-Challenges for the future. J. Dairy Sci. 72:1627-1636. https://doi.org/10 .3168/jds.s0022-0302(89)79275-4.

Barbano, D. M., and J. L. Clark. 1990. Kjeldahl method for determination of total nitrogen content of milk: collaborative study. J. AOAC Int. 73:849-859.

Barbano, D. M., J. L. Clark, and C. E. Dunham. 1988. Comparison of the Babcock and ether extraction methods for determination of fat content of milk: Collaborative study. J. AOAC Int. 71:898-914.

Barbano, D. M., and J. M. Lynch. 2006. Major advances in testing of dairy product: Milk components and dairy product attribute testing. J. Dairy Sci. 89:1189-1194.

Holroyd, S. 2011. NIR analysis of cheese - A Fonterra perspective. NIR News 22:9-11.

Hooi, R., D. M. Barbano, R. L. Bradley, D. Budde, M. Bulthaus, M. Chettiar, J. Lynch, and R. Reddy. 2004. Chemical and Physical Methods. Pages 385-391, 408-434, 442-460 in Standard Methods for the Examination of Dairy Products. 17th ed. H. M. Wehr and J. F. Frank, ed. American Public Health Association, Washington, DC.

Kaylegian, K. E., J. M. Lynch, G. E. Houghton, J. R. Fleming, and D. M. Barbano. 2006a. Calibration of mid-infrared milk analyzers: Modified milk versus producer milk. J. Dairy Sci. 89:2817-2832.

Kaylegian, K. E., J. M. Lynch, G. E. Houghton, J. R. Fleming, and D. M. Barbano. 2006b. Modified versus producer milk calibration: Mid-infrared analyzer performance validation. J. Dairy Sci. $89: 2833-2845$.
Kaylegian, K. E., K. E. M. Lynch, J. R. Fleming, and D. M. Barbano. 2009. Influence of fatty acid chain length and unsaturation on midinfrared milk analysis. J. Dairy Sci. 92:2485-2501.

Lynch, J. M., and D. M. Barbano. 1999. Kjeldahl Nitrogen analysis as a reference method for protein determination in dairy products. J. AOAC Int. 82:1389-1398.

Lynch, J. M., D. M. Barbano, M. Schweisthal, and J. R. Fleming. 2006. Precalibration evaluation procedures for mid-infrared milk analyzers. J. Dairy Sci. 89:2761-2774.

Margolies, B., M. C. Adams, J. Pranata, K. Gondoutomo, and D. M. Barbano. 2017. Effect of uncertainty in composition and weight measures in control of cheese yield and fat loss in large cheese factories. J. Dairy Sci. 100:6822-6852.

McKenna, D. 2001. Measuring moisture in cheese by near infrared absorption spectroscopy. J. AOAC Int. 84:623-628.

Rodriguez-Otero, J. L., M. Hermida, and A. Cepeda. 1995. Determination of fat, protein, and total solids in cheese by near-infrared reflectance spectroscopy. J. AOAC Int. 78:802-806.

Sjaunja, L. O., inventor. 1999. Product for dispersing of foodstuffs for analytical purposes. L. O. Sjaunja Aktiebolag. Uppsala (SE), assignee. EU Pat. No. 99850090.4.

Varcoe, J. S. 2001. Coulometry, osmometry and refractometry. Chapter 14 in Clinical Biochemistry: Techniques and Instrumentation: A Practical Course. World Scientific Publishing Co. Pte. Ltd., River Edge, NJ. 14:1-22.

Wojciechowski, K. L., C. Melilli, and D. M. Barbano. 2016. A proficiency test system to improve performance of milk analysis methods and produce reference values for component calibration samples for infrared milk analysis. J. Dairy Sci. 99:6808-6827. 